\title{
"HERMANO LOBO FUE EL PUÑETAZO EN LA MESA QUE LA PRENSA DEL FRANQUISMO NECESITABA PARA DESPERTAR". Entrevista a Ángel García Pintado ${ }^{1}$
}

\author{
Ramón Tena Fernández \\ Universidad de Extremadura \\ Cáceres, España \\ rtena@unex.es
}

\section{RESUMEN / ABSTRACT}

La revista Hermano Lobo nace durante la dictadura franquista, contexto histórico en el que aunque la censura indica que ya no es de consulta obligatoria, es cierto que sigue actuando. El semanario fue secuestrado en dos ocasiones, sufrió serias denuncias y tuvo que pagar cuantiosas multas por publicar contenido humorístico. Sin embargo, ninguna de estas sanciones acaeció durante el tiempo que la dirigió Ángel García Pintado; por ello es pertinente registrar su testimonio biográfico. Él es memoria viva del franquismo y nos documenta en primera persona cómo confeccionó un modelo de revista capaz de hacer chistes críticos sin despertar la ira censora. Un control al que él siempre estuvo expuesto y del que puede hablar con criterio, ya que además de dirigir Hermano Lobo, se dedicó al teatro independiente con el grupo Tábano y escribió más de cuarenta títulos teatrales, la mayoría de ellos prohibidos.

Palabras Clave: franquismo, censura, dictadura, prensa, cultura, Hermano Lobo.

“Hermano Lobo WAS THE FIST ON THE TABLE THAT THE FRANCO'S REGIME PRESS NEEDED TO WAKE UP”. AN INTERVIEW to ÁNGEL GARCía PINTADO

Hermano Lobo magazine was born during Franco dictatorship, historic context that, despite censorship states that mandatory consultation is not a must anymore, it is certain that it continues operating. The weekly magazine was hijacked twice, it suffered serious complaints

1 Este trabajo se incluye en las actividades realizadas por el Grupo de Investigación "LIJ" del Catálogo de grupos de la Junta de Extremadura (SEJ036), Coordinado por José Soto Vázquez. Ayudas cofinanciadas por FONDOS FEDER. Programa Operativo FEDER de Extremadura 2014-2020. No de Expediente GR18026. 
and it had to pay numerous fines for publishing humoristic content. However, none of these penalties occured along the time that Ángel García Pintado was its director, therefore it is relevant to record his bibliographic testimony. He is an alive memory of Franco's regime and provides us with information in first person that explains the way he developed a magazine model capable of creating critical jokes without being a censure target. A control which what he always was exposed and he can discuss with criteria because, not only he run Hermano Lobo, but also he engage in independent theatre with Tábano's group and wrote fourteen plays, forbidden most of them.

KEYWORDS: Franco's regime, censure, dictatorship, press, culture, Hermano Lobo.

\section{PRESENTACIÓN}

El semanario Hermano Lobo publica su primer número el 13 de mayo de 1972, nace sin previo aviso, sin campaña de marketing, con pocos recursos económicos y bajo una soterrada censura protegida por la Ley de Prensa de 1966. Además de estos condicionantes, la revista se define en portada como un semanario de humor, característica que según acreditan los informes de censura nunca agradó al Régimen.

Cualquier chiste por inocuo que fuera tenía altas probabilidades de considerarse una ofensa para el Estado o una crítica hiriente y de mal gusto a su nacionalcatolicismo. No contentos con esto, a sabiendas de que los censores estaban siempre al acecho, el semanario incorporaba una sección denominada "7 preguntas al lobo", entre las cuales nunca faltó aquella que se interesaba por saber cuándo acabaría la censura.

Todos estos caracteres hacían presagiar un final poco alentador para la revista, parecía haber nacido con el afán de inmolarse, de hecho, en sus presentaciones públicas nunca faltó el comentario de "estáis locos". No obstante, por sorprendente que parezca, la revista salió al mercado con una tirada inicial de 100000 ejemplares, su éxito fue apoteósico y en cuestión de poco tiempo sobrepasó los 150 000, una cifra que en momentos puntuales revalidó su aceptación llegando a tiradas cercanas a los 176000 ejemplares. Lógicamente, cuanto mayor fuese su difusión mayor sería la vigilancia censora, pues sus ideas llegaban a un elevado número de lectores.

Sin embargo, la revista, aunque con multas, denuncias y un par de secuestros en su trayectoria, nunca registró supresiones en su contenido. Un hecho extraño si tenemos en cuenta que los mismos colaboradores e ilustradores que componían su plantilla editorial, eran los que estaban seriamente vigilados por la censura. Algunos incluso con un juicio militar, como era el caso de Andrés Rábago, que hizo la primera portada de Hermano Lobo, otros como Forges, tuvieron que rendir cuentas ante un Consejo de Guerra por sus ilustraciones. En cualquier caso, dejando estos enigmas aparte, no cabe duda de que el semanario tuvo un éxito apoteósico y eso en palabras de Manuel Vicent se debe a su crítica, ácida y sarcástica. Leyéndola te sentías libre, satisfecho, diferente. Presentaba un humor fresco y renovado que supuso una explosión totalmente inesperada y la creación de un nuevo lenguaje con el que se abordaba mucho más que contenido político. 
A la cabeza de este modelo de revista estuvo Ángel García Pintado, el primer director de Hermano Lobo, que tras escuchar la propuesta de Chumy Chúmez (promotor inicial del semanario) y contar con el beneplácito de Ezcurra (propietario de Triunfo y Hermano Lobo) accedió a liderar este proyecto. La pregunta es tan obligada, como difícil su respuesta ¿Quién era García Pintado y por qué su elección? Por ello es necesaria la entrevista que en líneas sucesivas ofrecemos. Lo que sí podemos avanzar es que tenía méritos probados para ejercer como tal y una dilatada experiencia tanto en prensa como en teatro. Trabajó para La verdad de Murcia, ejerció como redactor jefe en Cuadernos para el diálogo, colaboró en Por favor, formó parte de la agencia de noticias Efe y, además de ser un nombre destacado en el teatro independiente del franquismo, obtuvo una plaza en el diario $A B C$.

Este será un hecho destacable, ya que en el periodismo de la época los puestos de responsabilidad o la permanencia en una editorial estaban ligados a la cadena de favores o a los servicios prestados al Régimen durante la Guerra Civil. Sin embargo, García Pintado obtuvo su lugar en la redacción por oposición académica, aunque abandonaría el cargo por sus discrepancias con la dirección dejando su puesto en el periódico. El porqué de estas discrepancias, los diferentes modelos de censura no oficial que vivió en su redacción y las posibilidades de informar sobre la actualidad de la época nos las documenta en las páginas venideras. Un recorrido periodístico e histórico que haremos con carácter cronológico por su trayectoria en prensa durante la dictadura franquista y donde nos centraremos con especial detalle en su labor como director de Hermano Lobo. Un espacio que necesita ser documentado, pues hasta la fecha, por sorprendente que parezca, ha sido atendido desde la óptica ofrecida por su fundador (Ezcurra) o su promotor (Chumy Chúmez), pero no se ha preguntado a quién realmente estuvo a cargo de la dirección del semanario. Un aspecto necesitado de luz porque los intereses fueron muy distintos. Mientras que a los promotores, por razones obvias, le interesaba mayoritariamente la viabilidad económica de la revista, a la dirección le preocupa más la parte cultural, la creación de un formato con identidad propia y la defensa de las libertades con un humor irónico.

El hecho de que hasta la fecha el grueso bibliográfico se haya interesado solo por los autores que colaboraron en la revista y de aquellos que la fundaron ha derivado en que algunos mitos, sin fundamento, hayan sido tomados como verdades categóricas. La falta de un contraste documental y la carencia de cotejo de distintas fuentes de información han apoyado un discurso histórico sobre la trayectoria de la revista que no siempre ha sido fiel a la realidad. Además, se olvida que tras la Ley de Prensa e Imprenta de 1966, quien tenía que asumir responsabilidades con la censura en caso de conflicto era su director por consentir la publicación de sus colaboradores.

No se entiende, cómo hasta la fecha el foco de las investigaciones se deposite casi en exclusividad en escritores e ilustradores, cuando la mayoría de ellos reconoce ignorar lo que la censura estimaba de sus trabajos. Quienes lidiaban con la administración censora y quienes pagaban las consecuencias de sus enfados eran los directores y los redactores jefes. Por tanto, qué necesidad hay de elucubrar suposiciones sobre los objetivos editoriales de Hermano Lobo, sus inspiraciones en prensa extranjera y el clima que se vivía dentro 
de la redacción, si tenemos la posibilidad de que la fuente primaria nos relate en primera persona su trayectoria. Un testimonio que podemos contrastar con aquellos que estuvieron bajo su mando en la revista e incluso con los datos que registran los legajos documentales que aún conserva el archivo de la censura.

RTF: Antes de abordar su trayectoria en prensa y la dirección en Hermano Lobo contextualicemos la época y el panorama cultural ¿Cómo definiría el periodismo de los años 60 y cómo fue su incursión en el medio?

AGP: Es una época naturalmente de represión, muy marcada por el nacionalcatolicismo. No había ninguna posibilidad de meterte en un periódico o en una revista, o al menos eran muy pocas las opciones, la mayoría de estas redacciones estaban copadas por los que habían hecho la guerra, por falangistas preferentemente.

Yo empiezo a trabajar antes de ir a la Escuela de Periodismo, que en aquella época eran tres años. Además, te confieso que a mí me suspendieron el acceso hasta en dos ocasiones, pero poco después se creó la Escuela de Periodismo de la iglesia fundada por el cardenal Herrera Oria. Con este motivo hice una memoria, me la aprobaron y fui aceptado para ingresar en esta formación. También te diré que allí nos metieron a toda la morralla que no habíamos sido aceptados en la escuela oficial, porque no olvides que esta escuela pertenecía a lo que hoy es el Ministerio de Cultura y por aquel entonces dependía del Régimen. Así se controlaba a los periodistas en activo y a los que se estaban formando. En cualquier caso, tuvimos muy buenos profesores, eran casi todos catedráticos. Además, cuando salíamos de allí hacíamos una especie de reválida ante un tribunal que pertenecía a la escuela oficial, ellos nos examinaban y nos daban el título.

Antes de todo esto ya trabajaba haciendo paparazzismo, porque nosotros importamos a España los primeros paparazzis de Milán y de Roma. Pero era un paparazzismo que nada tiene que ver con el de ahora, se destinaba a personalidades elitistas, reyes y princesas mayoritariamente, como Fabiola y Balduino de Bélgica, o estrellas de primer nivel reconocidas internacionalmente, como Ava Gadner y Charlton Heston que veraneaban por nuestro país. Esto lo cuento para describir el contexto periodístico de la época, porque es una muestra representativa de lo poco que se podía documentar. Solo Radio Nacional podía emitir noticias, Radio Nacional y por decreto. Sin embargo, La Ser, Intercontinental o La Cope no podían informar aunque dispusiesen de datos contrastados.

Entiendo que cuando indica que informaban por decreto, se refiere a las consignas que desde la censura imponían con motivo de la Ley de Prensa de 1938 ¿Cómo era trabajar bajo la sombra de esta ley que había sido creada durante la guerra?

Exacto, nos situamos en la etapa de la censura previa y obligatoria. Yo me voy porque quiero conocer el periodismo de provincias. Empiezo en La Verdad, un diario de Murcia, trabajo en su delegación de Alicante y opto por esta opción consciente de que sería mi escuela, porque del periodismo de provincia se aprende mucho. Pero es una época en la que cualquier palabra, diálogo o conversación que pudiese surgir con cierta espontaneidad era aprovechada por cualquiera. 
El trabajo en prensa no abundaba, los cargos importantes eran otorgados por cadena de favores al Régimen y si querías optar por méritos propios bastaba con que el Estado te denegara el carnet de periodista para que ni tan siquiera pudieras concurrir a la dirección de cualquier medio. Te pongo un ejemplo de algo que me ocurrió a mí y que revela a la perfección cómo se aprovechaban las oportunidades: Cuando tomé la decisión de irme a La Verdad me encontré con Francisco Umbral en la calle Alcalá de Madrid, le confesé mi futuro profesional y no me entendía, no veía lógico que lo dejara todo para irme a un periodismo de provincia. La sorpresa me la llevé yo cuando, ni transcurrida una semana en esta nueva redacción, llamé por teléfono a mi antiguo trabajo y descubro que a Francisco Umbral le había bastado un par de días para quedarse con mi puesto. Algo respetable pero que evidencia muy bien cómo se aprovechaba cualquier atisbo de palabra no comedida; por eso te digo que fueron unos años en los que aprendí mucho y a nivel profesional hice de todo.

De La Verdad pasó a trabajar en ABC, todo un hito para cualquier periodista de la época. Sin embargo, según los datos que manejo, su experiencia fue como la de vivir en una cárcel de oro. ¿Cómo llegó a ABC y por qué su dimisión?

En la década de los años sesenta convocan unas oposiciones nacionales para el diario $A B C$, solo tres plazas. Me presenté a las pruebas y me volví a Alicante pensando que había suspendido, pero no, todo lo contrario, recibí una carta con el aprobado. En aquellos años trabajar para ese periódico era estar en primera línea, era lo máximo. Además, yo no estaba politizado, era el clásico hombre producto del franquismo que defendía la neutralidad, el rigor informativo y la veracidad de la noticia. En esos mismos años dentro de $A B C$ también colaboraban González Ruano, José María Pemán y José María de Areilza. Estoy cinco años en esta redacción hasta que se produce el juicio de Burgos contra los etarras. Una de las noticias más importantes surgidas durante el tardofranquismo; el hecho causó un gran revuelo y supuso un punto de inflexión en la dictadura porque este escándalo se sumó a algunas manifestaciones de movimientos sociales anti-franquistas. Pero por si no fuera poco, el juicio de Burgos venía precedido de la noticia del "suicidio" de un estudiante, Ruano, que todos sabíamos que en realidad lo tiró la policía por una ventana y dijeron que se había suicidado. Esto me hizo ver que estábamos aportando una información sesgada, de fuente policial, poco objetiva y muy tendenciosa, aquí comencé a apreciar que los que allí trabajábamos estábamos un poco politizados, o al menos comenzábamos a estarlo.

Lo peor es que esta represión no venía solo de la censura, el control estaba dentro de la propia redacción editorial, y con la celebración del juicio de Burgos se ejerció de forma descarada. Nos visitaba todas las tardes el padre de Ruiz Gallardón que era editorialista de $A B C$, repasaba las pruebas de imprenta que Miguel Torres nos mandaba desde Burgos y él directamente iba tachando y añadiendo de su pluma las consignas y apreciaciones que él consideraba. Esto es tan solo un ejemplo; la situación se fue haciendo extensible al resto de compañeros, el control dentro de la redacción fue alimentando la animadversión. Se llegó a una situación de malestar creciente que desencadenó con la sentencia del juicio de Burgos y la firma de siete penas de muerte. No olvidemos que el 
caudillo firmó estas sentencias, es cierto que luego las conmutó, pero primero las firmó sin importarle en absoluto el revuelo nacional e internacional, las manifestaciones sociales y la oposición del papa Pablo VI.

Ese mismo día nos fuimos tres compañeros de $A B C$, Díaz Plaja (hijo del académico), Enrique Iparaguirre, que luego fue senador por el PSOE y yo. Ninguno de los tres nos conocíamos de nada porque trabajábamos en distintos turnos y secciones, pero todos nos fuimos con sendas cartas a Torcuato Lucas de Tena, que era el director del periódico por aquel entonces. Que tres personas renuncien el mismo día, sin tener ningún tipo de relación y carentes totalmente de cualquier coordinación o premeditación entre sí sirve para hacerse una idea del contexto cultural y periodístico que estábamos viviendo. Parte de mi carta de renuncia la reprodujo Radio Moscú, Radio España Independiente y el diario Le Monde, imagínate lo que suponía eso en la dictadura y represión del diciembre de 1970.

Desafiar al gobierno y además pregonarlo públicamente como sucedió con su carta de renuncia solía tener consecuencias ¿Cuáles fueron las suyas?

Yo era un inconsciente, totalmente. Hasta el punto de que yo iba por la calle y la gente se cruzaba a saludarme o a comentarme que era un tipo valiente. Estas valoraciones venían sobre todo por parte de los actores, porque yo estaba relacionado con el mundo del teatro; por aquel entonces ya había ganado el premio Guipúzcoa. Los sectores de izquierda, los ámbitos comunistas y otros partidos que tradicionalmente desconfiaban de los periodistas que trabajábamos para $A B C$, se aproximaron a mí.

Aquí fue cuando yo comencé a politizarme, un cambio personal que además coincide con la apertura de la revista Cambio 16. Por aquel entonces su dueño tiene una entrevista conmigo y me propone que ejerza de redactor jefe. Una revista que, aprovecho para informarte de algo que no todo el mundo sabe, y es que el franquismo le otorgó la licencia de publicación confiando en que sería una revista especializada en economía, no de información general como luego fue. En cualquier caso, la propuesta que me hicieron la agradecí, pero la decliné. Renuncié a ella porque estaba un poco harto del periodismo y le dije a su director, la verdad, que me iba a ir con el grupo de teatro Tábano.

Después de abandonar el periodismo por iniciativa propia y dedicarse vocacionalmente al teatro retoma la profesión para dirigir Hermano Lobo. ¿Cómo accede a su dirección y por qué acepta esta propuesta después de haber rechazado tantas otras como la de Cambio 16 ?

La propuesta surgió con una llamada de teléfono de Chumy Chúmez, al que yo conocía pero solo por sus dibujos y por su genialidad, nada más. Recuerdo perfectamente nuestra conversación:

- Queremos hacer una revista de humor y queremos que tú seas el director.

- ¿Con qué dibujantes cuentas?

- Cuento con Ops, Forges, Peris, Summers y yo mismo, de momento.

- No necesito saber más. Acepto pero con la condición de que mi misión no sea solo la de poner mi nombre y el carné de periodista que necesitáis para el Ministerio. Si contáis conmigo voy a llevar la revista, naturalmente porque de esto sé un poco. 
- De acuerdo, pero claro, ya sabes que allí hay un talante muy democrático.

- Eso no me lo tienes que decir. Porque de talante democrático, ya he aprendido bastante en los grupos de teatro independiente.

- Entonces, ¿aceptas?

- Chumy, acepto porque sé que va a ser un éxito.

- ¿De verdad?

- Seguro, porque con esa gente que me has dicho no cabe duda de que esto será un éxito.

Esto responde a tu pregunta, accedo a la dirección por invitación de Chumy Chúmez y porque el proyecto tenía un futuro muy prometedor, al que consideraba que podía aportar mi experiencia. De hecho, yo firmo el contrato con ellos en 1972, unos meses antes del estreno de Hermano Lobo, porque el primer número que se publica sale el 13 de mayo de 1972 con mi nombre entre los créditos iniciales, algo que se mantiene hasta el número 67 del 18 de agosto de 1973.

Del estreno de Hermano Lobo solo se sabe que vio la luz de manera inesperada, sin previo aviso y aparentemente sin una estrategia publicitaria. ¿Se vaticinaba su éxito?

Hermano Lobo fue un auténtico boom y, aunque ahora todo el mundo se enarbole como un acérrimo defensor desde sus orígenes, cuando presentamos la revista no se confiaba en ella. De hecho, en un programa radiofónico llamado Hora 25 nos hicieron una entrevista para La Cadena Ser, recuerdo que fue por la noche y que el espacio era como el equivalente al 24 Horas que tenemos en la actualidad. Pues bien, recuerdo perfectamente que llevamos el número 1 de la revista, el que iba a salir en los quioscos al día siguiente. El presentador nos lo quita de las manos, lo revisa con desprecio y con cierto desdén nos pregunta ¿Y de esto cuántos vais a tirar? a lo que yo respondí: ya hemos tirado 100.000 ejemplares. Su reacción fue rotunda y directa: ¡Estáis locos! Pero a la mañana siguiente para las dos de la tarde, esa locura llamada Hermano Lobo ya se había agotado en todos los quioscos de Madrid, e inmediatamente me llamaron a casa de ese mismo programa, para que pudieran ir nuestros colaboradores a comentar el éxito de la revista.

Ese rotundo éxito del número uno de la revista llevaba como carta de presentación un dibujo de OPS en la portada. Me consta que el OPS del franquismo hacía sátira, no chistes y además sus ilustraciones eran muy negras ¿Por qué se elige su trabajo para lanzar una revista de humor cuando él no hacía humor?

En los primeros números prevalecía mucho el dibujo y había poco texto. El proyecto inicial con el que me encontré estaba poco armado era una revista que si la comprabas en la estación de Atocha no llegabas ni a Aranjuez con ella. Porque realmente se te agotaba enseguida, no había apenas lectura. Entonces me metí de lleno con Castaño (veterano confeccionador de la revista Triunfo), tarde y noche en la redacción para hacer un semanario fuerte y con capacidad para mantener su lugar en el tiempo. Pero aunque compartíamos diagramador con la revista hermana, mi concepto era que la portada de Hermano Lobo tuviese identidad propia, tenía que ser como un puñetazo que marcara y que llamara la atención. Chumy Chúmez hizo una propuesta con Don Quijote por los 
campos de Castilla y con alguna frase por medio, pero eso no casaba con mi idea. A pesar de ser él el promotor de la revista le dije claramente que apreciaba mucho su dibujo pero que no lo iba a integrar en la portada.

No podemos olvidar que Chumy a fin de cuentas no dejaba de ser un empresario, al igual que Ezcurra (propietario de Triunfo y Hermano Lobo) y por ello también los intereses a veces eran diferentes. Le reconocí que su trabajo lógicamente tenía cabida en la revista pero como un chiste interno, para la portada yo buscaba un golpe de efecto y sabía que eso lo podía conseguir con OPS, Andrés Rábago. Entonces yo no tenía la amistad que tengo hoy con él, lo acababa de conocer, pero confiaba en sus posibilidades y dijimos veamos qué se le ocurre. Suya y solo suya fue la idea del torero sentado posando con la bandera de EEUU a modo de capote. En la época del franquismo, en el año de 1972, ese fue el real puñetazo que yo buscaba. Efectivamente, tal y como indicas en la pregunta reconozco que defender la idoneidad de OPS no me fue fácil, tenía merecida cabida, pero como bien dices por aquel entonces hacía dibujos con vísceras y muertos.

De todos modos, la idea era que cada semana uno de nuestros ilustradores se encargara de hacer la portada. Así también dábamos lugar a diferentes estilos y aunque Andrés no hiciera chistes yo lo defendía hasta la muerte. Poco a poco nuestra amistad se hizo fraterna, somos como hermanos y el equipo que hicimos entre todos nos llevó hasta los 176000 ejemplares por tirada. Una cifra muy respetable en el franquismo.

\section{¿Por qué la revista salió al mercado de forma repentina y sin campañas de marketing que garantizaran una buena acogida?}

Era el momento y había que aprovecharlo. Triunfo además de sancionado estaba suspendido durante meses y por ello Ezcurra, su director, terminó accediendo a la propuesta de Chumy Chúmez que no partía de cero, ya llevaba tiempo tratando de convencerle. Por otra parte, la gente estaba cansada de La Codorniz, sus páginas entrañaban un humor viejo; más que un humor rancio era fascista. Porque La Codorniz se crea en las trincheras nacionales. Su primer director fue Miguel Mihura, pero después vino Álvaro de la Iglesia, que fue a la División Azul a luchar con las tropas de Hitler, por ello te digo que está inspirada en las trincheras de las ametralladoras. Pese a todo ello, naturalmente La Codorniz había tenido un éxito bárbaro y también hay que precisar que en ciertas cosas muchos de los que formaron parte de la División Azul fueron en alguna medida engañados. Otro de los que formaron parte de sus filas fue Luis García Berlanga, y mira que cine hizo luego.

Centrándonos en la revista de Hermano Lobo y teniendo en cuenta que este semanario compartía cúspide directiva con Triunfo ¿Fue fácil mantener líneas editoriales diferentes entre revistas hermanadas?

En el propósito de mantener este distanciamiento estuvo el comienzo del fin y ello era evidente en el ambiente de trabajo que cada vez era más agrio. Todo surge cuando unos cuantos de nosotros solicitamos la creación de un Consejo de Redacción y con este proyecto algunos nombres clave de Triunfo como Haro Tecglen (subdirector) se ponen nerviosos. Como bien sabes, él tenía unos cuántos seudónimos con los que firmaba sus 
artículos, allí era lo que se denomina como un santón y a partir de ahora ya no valdría con decir "publicadme esto", ahora sería necesaria la aprobación del Consejo.

El primer enfrentamiento que tuve con Haro Tecglen (número dos de Triunfo) se origina cuando Ezcurra (director de Triunfo) me pasa un artículo de Eduardo Haro y me dice a ver qué le parece esto para Hermano Lobo, lo leo, subo al despacho de Ezcurra y le digo: está muy bien escrito, como todo lo que escribe Eduardo Haro, pero no tiene ni puta gracia. Tal cual se lo dije se lo trasmitió a él y desde entonces me cogió una ojeriza importante.

Mi respuesta fue totalmente objetiva, una de las premisas que teníamos en Hermano Lobo era que el material seleccionado para publicar tuviera gracia. En esta idea me mantuve muy firme desde los orígenes de la revista y me trajo consecuencias porque quedé mal incluso con amigos personales. Me enviaban sus artículos y les tenía que decir, que no iban a entrar en imprenta porque no se ajustaban a las necesidades de la revista. En cuanto me fui de la redacción entró una nómina de escritores que aunque escribieran bien o muy bien no tenía nada que ver con la naturaleza con que fue concebida Hermano Lobo.

Yo llevaba ahí una disciplina rígida en ese aspecto, porque sabía que nuestro público era un público de izquierdas. Es más, con el tiempo me he enterado de que activistas de Comisiones Obreras y de UGT hasta que no terminaban de leer Hermano Lobo, no empezaba la reunión y eso me lo han dicho ellos mismos. Gracias a esta fidelidad la revista se convirtió en todo un fenómeno y hacíamos gira por toda España. Por eso no podía permitir escenas como la que me ocurrió con Chumy Chúmez, que dijo en medio de una conferencia que la revista la hacíamos para ganar dinero. Y esto lo verbalizó en un colegio mayor en Sevilla. En un contexto universitario como este, no se podían decir estas cosas. Cuando llegamos al hotel, yo le eché una bronca tremenda y recuerdo que le dije: Oye, macho, esto es una revista politica, dentro de un orden. Y así fuimos sumando hasta que me echaron.

¿Había coherencia entre el discurso con el que se presentaban las revistas Hermano Lobo y Triunfo con el quehacer profesional de sus fundadores? ¿Sus decisiones directivas eran cuestionadas?

Cuestionada no, pero vigilada sí. Te lo expongo con un suceso real que documenta la pregunta que me has formulado. Una buena mañana recibo una llamada de teléfono, es Ezcurra, el impulsor de mi revista y el director de Triunfo, que me dice: Pintado, no hace falta que venga por las tardes, con que lo haga solo por la mañanas es suficiente. Yo le digo que no, que estoy acostumbrado a ir mañana y tarde a mi despacho y así lo seguiré haciendo. Con lo cual él por iniciativa propia me pone a una secretaria, supuestamente para ayudarme, cuando en realidad era para que me vigilara. Lo sé a ciencia cierta porque a toro pasado te digo que la chica era una "amiga" que él tenía y le venía de perlas para que le informara de lo que allí sucedía.

En lo que respecta a tu primera pregunta sobre la coherencia de predicar con el ejemplo, te indico otro suceso que va a colación con la información anterior. Una tarde llego a la redacción, subo al despacho de Ezcurra (director de Triunfo) y me encuentro en la antesala con una mujer guapísima que no sabía quién era porque no la había visto 
antes. Cuando bajo de nuevo a mi oficina le cuento a mi secretaria y le pregunto por ella, para saber qué quería. Me dice que es Miss Asturias y que venía a ver expresamente al Sr. Ezcurra. ¿Qué pasa que le van hacer una entrevista en Triunfo? Y me dice: No, no, viene solo por un asunto personal.

Me voy a la cafetería y me encuentro allí con Haro Tecglen (subdirector) Víctor Márquez Reviriego, y César Alonso de los Ríos (redactores jefes) Les cuento la anécdota y se ríen a carcajadas. Allí me entero de que Ezcurra tenía la exclusiva de los certámenes españoles de belleza. Sí, la exclusiva de los concursos de miss España y miss Europa y todo ello al mismo tiempo que empleaba el discurso de que Triunfo era una revista de izquierdas muy feminista. Yo era muy ingenuo, de este tipo de cosas ni me enteraba, pero aquello no me casaba con el discurso que se ofrecía, para mí era un ambiente enrarecido.

La verdad es que no me resulta sorprendente porque los inicios de Triunfo eran muy distintos a los que han calado en la retina de cualquier español. Pero, ¿por qué se produce el cambio editorial?

Triunfo se convierte en una revista de progres, pero sus orígenes como bien has dicho eran los de una revista de cine, con Carmen Sevilla, Paquita Rico o Marujita Díaz. De hecho, estas dos últimas tuvieron una relación muy amistosa con Ezcurra, al igual que también la tuvo con otras dos folclóricas de la época. Hoy todo el mundo tiene la idea del izquierdismo de Triunfo y de su lucha por combatir la represión, pero se obvian muchos detalles. Antes de llegar a esta nueva filosofía de revista o a este ideario se hizo una encuesta de lectores y el público la enmarcaba como una revista falangista de posguerra. No iban mal encaminados, el hermano de Ezcurra era director general de TVE, un puesto que en la dictadura no era fácil de conseguir. Ellos eran falangistas o al menos lo habían sido, venían de Valencia con la camisa azul. Les dan la concesión de la revista como lo hacía el Estado con las viudas de coroneles o de capitanes que les concedían un estanco o un despacho de lotería nacional como pago por los servicios prestados.

Ese cambio al que aludes también obedece a un estudio de mercado que ellos hacen y sale que hay que darle un giro a la revista y hacer un contenido dirigido más a intelectuales y, sobre todo, con un discurso de izquierda, así es como nació el Triunfo que ahora todos conocen. El estudio se hizo en cuánto empezó a caer la tirada de ejemplares, en ese momento Ezcurra cogió miedo y encargó a los de Movie Récord un estudio de mercado que fuese revelador de la situación. Los resultados fueron los que evidenciaron que había que dirigirse a la juventud y así surgió el Triunfo progre.

Al investigar los orígenes de la revista e interesarnos por las características de su diseño siempre encontramos artículos con la afirmación de que fue un fiel reflejo de la francesa Charlie Hebdo. Sin embargo, una comparativa con números fechados en los mismos años no muestra tal similitud. ¿Realmente se inspiraron de los compañeros franceses o es un bulo que se ha dado por certero?

Algo de razón tienes. Yo estoy casado con una francesa y he viajado mucho a Francia y te digo con claridad que el parecido estaba en la portada pero dentro ya no se parece. Además 
tenían un papel muy flexible, el nuestro era más rígido y más blanco. Nos esforzamos en elegir la mejor imprenta de Madrid, que era Hauser y Menet. Allí acudía yo con el confeccionador a las páginas de imposición donde cuidábamos todos los detalles $\mathrm{y}$, en ocasiones, nos acompañaba Chumy Chúmez.

Juntos armamos una revista competitiva, de calidad, como "Dios manda", ajustada al milímetro y estudiada para que al lector le entrara la revista por los ojos nada más verla. Sin embargo, cuando dejé Hermano Lobo todo esto se descuidó, no por falta de gente válida, sino porque entró un batiburrillo de colaboradores y se perdía la identidad de la revista. Desde arriba se pusieron muy nerviosos y empezaron a hacer muchas tonterías. Por ejemplo: Yo era muy amigo de los pintores abstractos, de los constructivistas españoles y me gustaba mucho el arte y eso de alguna manera influye. Es decir, sabía que al público tenía que darle un producto no solo bueno, también bien presentado.

Sin embargo, Chumy Chúmez esto no lo entendía, él sabía mucho de arte y tenía un talento indiscutible pero no era pintor y este tipo de cosas no las cuidaba tanto como se debería o no era lo suficientemente crítico con ellas. Hoy mismo, preparándome esta entrevista he hecho una comparativa de números y que sí tú mismo la haces te das cuenta de que los primeros ejemplares se caracterizaban por una limpieza estética que no era tan apreciable en los últimos números. Y esto también marcaba la diferencia con respecto a la competencia. Pero, retomando tu pregunta, si de buscar similitudes se trata, Hermano Lobo se parecía a la francesa Le Canard enchaîné, un semanario que no tienen nada de publicidad y que vive solo de la venta. Nosotros sí que salimos a la calle con ese modelo, aunque con menos textos.

Revisando las sentencias judiciales de la censura y los alegatos del pliego de descargos de Ezcurra me consta que la economía de la empresa no era boyante. Si no había publicidad y la empresa estaba bajo mínimos ¿Cómo se financiaba Hermano Lobo?

No lo sé, pero sí te puedo decir que había un administrador que nos llevaba las cuentas, era Aramburu. Y en lo que respecta a la publicidad te puedo indicar que nuestro éxito puso muy celosos a los de Triunfo, porque ellos supusieron que nosotros nos íbamos a quedar en unos 15000 o 16000 ejemplares, algo menor, pero claro tan solo el primer número fue 100 000, cifra que mejoramos notablemente y además sin publicidad. Sobre la situación económica, tal vez te ayude saber que de ahí el único que tenía contrato era yo, los dibujantes no. Cuando a mí me echaron me correspondían 600000 ptas y conseguí un millón, si no no me iba y me lo dieron para que me callara, pero en mi condición personal eso de callarse no iba conmigo.

Por aquel entonces Triunfo ya no tenía mucha publicidad y los dibujantes pensaron "si a García Pintado le ha pasado esto, a nosotros que no tenemos ni contrato nos echan a la calle con mayor facilidad”. Por eso, se funda Por favor, donde Vázquez Montalbán me pide que haga algunos trabajos sobre teatro y en los primeros números encontrarás críticas teatrales con mi firma. Allí me acompañan también el novelista Juan Marsé, Maruja Torres y Peris que hacen Por Favor, junto a sus fundadores que tenían unos sueldos fabulosos. 
Ahora que hablamos de sueldos fabulosos, en El País he leído que las reuniones de Hermano Lobo se celebraban en el restaurante Picardías y que alli el bogavante y el champagne abundaban. Siendo la mayoría de ustedes humoristas, la pregunta tiene lógica ¿era ironía o realidad?

Hermano Lobo lo hacíamos en el sótano de la revista Triunfo, en el piso de abajo estaba mi despacho, y al lado se ubicaba la redacción con Cernuda y la secretaria que me puso Ezcurra. El espacio era pequeño, se trataba solo de un despachito y la verdad es que no necesitábamos más, porque casi todos los integrantes de la revista eran colaboradores. Y sí es cierto lo que comentas, Ezcurra (fundador) nos invitaba de vez en cuando a comer en el Picardías. Nos reuníamos de vez en cuando, era un restaurante del Madrid antiguo, donde se comía muy bien pero que no era de lujo. Era el punto de encuentro para todos los miembros de la redacción y donde también asistían los del piso de arriba, los que hacían Triunfo y algunas veces también venía Vázquez Montalbán.

En este restaurante se tomaban decisiones y se hacían propuestas. De hecho, en una de estas reuniones Manuel Summers, que era sobrino y ahijado de José María Pemán, uno de los escritores más apegados al franquismo, me dijo directamente: Pintado, creo que mi tío debería entrar en la revista porque es quien mejor escribe de España. Mi respuesta fue igual de directa que su propuesta: Ni hablar, mientras yo esté aqui tu tio no entrará porque esto es una revista de izquierda. Así se lo dije y se tuvo que callar. Y además, igual que te he hablado antes de las discrepancias, es de justicia que te reconozca que conté con el beneplácito de Ezcurra que me dijo: ¡Muy bien Pintado, bien dicho!

Se producían situaciones de este tipo y en parte también obedecían a las personalidades de cada uno. Por ejemplo, la actitud de Summers chocaba con la manera de ser de Andrés Rábago, un hombre discreto y escorado a la izquierda. Sin embargo, Summers, hijo del Gobernador Civil del Huelva, nos mandaba los chistes más burros que te puedas imaginar porque era un anarco, una especie de ácrata.

Para finalizar, según el material cotejado en el archivo, me consta que el humor siempre fue indigesto para el Régimen. Lo consideraban una burla, una ofensa. ¿Alguno de los chistes que publicaron tuvo consecuencias con la censura?

Durante mi dirección solo nos abrieron un expediente en el $n^{\circ} 7$ de la revista y fue con motivo de un artículo de Jimmy Jiménez Arnau, hijo de uno de los principales embajadores de Franco, un buen poeta, mejor escritor y gran humorista. Luego, cuando se casó con la nieta de Franco cambió su trayectoria profesional, pero por aquellos años era un buen fichaje para la revista. Él hizo un artículo que se llamaba La madre española, el texto estaba bien escrito y enaltecía la figura de la madre por todo lo alto, pero terminaba con la frase: "la madre española es tan perfecta que a veces hasta tiene marido".

Y tan solo por esta oración me pusieron un expediente, pero para uno que tuve durante mi dirección en Hermano Lobo tuvo que ser por un trabajo del hijo del embajador de Franco, Jiménez Arnau, que en teoría era falangista. No tuvimos más problemas porque frenábamos muchos chistes, sobre todo de Summers que nos enviaba algunos que eran muy bestias. La conclusión de todo esto es que los hijos de la oligarquía eran los más transgresores en sus publicaciones. 
Expedientes no tuve más, pero llamadas de teléfono sí. Hermano Lobo nace en medio de una apertura retórica que era la que promovía Fraga Iribarne con su Ley de Prensa e Imprenta de 1966. En estos años, su director general me llamaba a las 8 de la mañana a mi casa, antes de ir a la oficina, para decirme en tono paternalista y amable: Oye, Ángel, como me río con vuestros casetes de "Mac Macarra", pero hombre este tema que ha tratado Emilio de la Cruz debería... Eran sugerencias a modo de amistad y como para prevenirme. Recuerdo que el que hacía las casetes más fuertes era Emilio, el que fuera Vicedecano de la Facultad de Derecho de la Complutense. A él le habían matado a su padre los socialistas en la guerra, pero para nada era un hombre sectario, ni tampoco de izquierdas. Lo que sí fue es el creador de un nuevo lenguaje popular que sería más tarde reconocido como "el cheli" y que luego, además, otros intentaron apropiarse de su autoría y genialidad.

\section{BIBLIOGRAFÍA}

Mora, Miguel. "El humor de los tiempos de la penuria triunfa otra vez". El País (digital): $9 / 01 / 2000$. 